\title{
Experimental Investigation and Comparison of the Thermal Performance of Additively and Conventionally Manufactured Heat Exchangers
}

\author{
Ana Vafadar *(D), Ferdinando Guzzomi and Kevin Hayward
}

School of Engineering, Edith Cowan University, Joondalup, WA 6027, Australia; f.guzzomi@ecu.edu.au (F.G.); kevin.hayward@ecu.edu.au (K.H.)

* Correspondence: a.vafadarshamasbi@ecu.edu.au; Tel.: +61-863044685

Citation: Vafadar, A.; Guzzomi, F.; Hayward, K. Experimental Investigation and Comparison of the Thermal Performance of Additively and Conventionally Manufactured Heat Exchangers. Metals 2021, 11, 574. https://doi.org/10.3390/ met11040574

Academic Editors: Mohammad J. Mirzaali and Amir A. Zadpoor

Received: 26 February 2021

Accepted: 25 March 2021

Published: 1 April 2021

Publisher's Note: MDPI stays neutral with regard to jurisdictional claims in published maps and institutional affiliations.

Copyright: (C) 2021 by the authors Licensee MDPI, Basel, Switzerland. This article is an open access article distributed under the terms and conditions of the Creative Commons Attribution (CC BY) license (https:/ / creativecommons.org/licenses/by/ $4.0 /)$.

\begin{abstract}
Air heat exchangers (HXs) are applicable in many industrial sectors because they offer a simple, reliable, and cost-effective cooling system. Additive manufacturing (AM) systems have significant potential in the construction of high-efficiency, lightweight HXs; however, HXs still mainly rely on conventional manufacturing (CM) systems such as milling, and brazing. This is due to the fact that little is known regarding the effects of AM on the performance of AM fabricated HXs. In this research, three air HXs comprising of a single fin fabricated from stainless steel $316 \mathrm{~L}$ using AM and CM methods-i.e., the HXs were fabricated by both direct metal printing and milling. To evaluate the fabricated HXs, microstructure images of the HXs were investigated, and the surface roughness of the samples was measured. Furthermore, an experimental test rig was designed and manufactured to conduct the experimental studies, and the thermal performance was investigated using four characteristics: heat transfer coefficient, Nusselt number, thermal fluid dynamic performance, and friction factor. The results showed that the manufacturing method has a considerable effect on the HX thermal performance. Furthermore, the surface roughness and distribution, and quantity of internal voids, which might be created during and after the printing process, affect the performance of HXs.
\end{abstract}

Keywords: additive manufacturing; metal 3D printing; conventional manufacturing; heat exchange; pressure performance; thermal performance

\section{Introduction}

Heat exchange has high industrial importance from environmental perspectives, in which it is applied to different industrial products such as electronic devices, gas turbines, and small-sized engines. These products need to dissipate heat in order to operate successfully, and a significant temperature increase may lead to high thermal stresses and/or affect the product's reliability and overall performance [1]. Therefore, it is crucial to provide sufficient cooling for such products. Heat exchangers (HXs) are used to transfer thermal energy between two or more mediums, referred to as heat-carrying mediums, or between two or more fluids in thermal contact by means of conduction, convection, and radiation [2]. These heat transfer mechanisms are dependent on the HX material properties, such as heat transfer capacity, melting points, surface finish, and geometry. The present research focuses on the convection system, which is widely used in different industry sectors such as electronics, aerospace, and automotive.

One of the preferred fluids to use in convection systems is air because it provides a simple, reliable, and cost-effective solution. In this system, the heat exchange device(s) absorb heat and dissipate it to the air through either natural or forced convection [3]. A typical heat exchange device includes extended surfaces [4], also known as cooling fins. The fins come in different shapes, such as strip fins and circular fins.

It is critical to evaluate the thermal performance and thermal resistance of fins when designing and/or selecting heat exchange devices [5]. Different researchers have found 
that these criteria are dependent on surface-to-area contact, surface finish, and material parameters [6]. For instance, Wong et al. [7] designed heat sinks with increased surface area to enhance the heat exchange coefficient. As mentioned in Table 1, the pressure drop of the novel HX with V-shaped structures was 50\% lower than that of the HX with pin fin arrays. Ventola et al. [8] observed that the surface roughness of fins enhanced the heat transfer coefficient remarkably, compared to smooth external fins, because of the disruption of the thermal boundary layer. The experimental results showed that the performance of rough finned surfaces was 35\% lower on average than that of smooth surfaces. Oguntala et al. [9] concluded that enhanced thermal management could be obtained using rough surface fins. Common materials used in HXs are aluminium, aluminium-brass, copper, coppernickel, steel, and stainless steel [10]. These materials may also need to meet criteria such as high corrosion resistance, durability, fatigue resistance, and thermal and creep properties to boost the HXs efficiency. Thompsonet et al. [11] applied a multi-layered Ti6Al4V to water-filled HXs. The experimental results demonstrated that this additive fabricated HX increased the thermal conductivity by up to $500 \%$, compared with solid titanium alloy HXs. Ceramic-metal composites have been applied in the construction of HXs in solar power plants [12]. The results showed that $\mathrm{ZrC} / \mathrm{W}$-based $\mathrm{HX}$ s could strongly outperform nickel-superalloy-based printed-circuit HXs and at a lower cost.

Although HXs have mainly relied on conventional manufacturing methods such as extrusion, brazing, casting, traditional computer numerical control (CNC) machining, or a combination of these techniques [7], recently, some researchers have studied the applications of additive manufacturing (AM) systems in the development of heat exchange devices have the significant potential to facilitate the development of the high-efficiency HXs due to the complex, geometric freedom this manufacturing technique offers. The majority of metal AM systems that have been used for heat exchangers apply powder bed fusion (PBF) processes $[17,18]$. Common metal PBF processes include direct metal laser sintering (DMLS), selective laser melting (SLM), electron beam melting (EBM), and direct metal laser melting (DMLM) [19]. Wong et al. [20] compared the heat transfer performance of AM heat sinks with cylindrical rectangular-rounded and aerofoil fins were fabricated by the SLM method from aluminium alloy AlSi10Mg. The experimental results showed that the heat performance of the rectangular-rounded heat sinks and the aerofoil heat sinks were $15.0 \%$ and $21.4 \%$ higher than that of the cylindrical fin structure. In another study, the capabilities of AM were examined. To do this, an aluminium alloy (AlSi10Mg) microchannel heat sink was manufactured using DMLS AM technology. AM capabilities allowed these authors to manufacture new geometries that could not be manufactured using traditional techniques. The performance of the new design was then compared with the original design [21]. The results showed that the laminar Nusselt number of the new design was $45 \%$ greater than that of the original design. Gerstler and Erno [22] developed a novel HX design to meet the harsh heat transfer and pressure characteristics requirements of a turbine engine. The mass and volume of the new HXs were reduced by about $66 \%$ while still maintaining the required constraints. Table 1 also provides some recently published studies on the AM-HX device, the material used, AM technology, and the main outcomes. Interested readers may refer to the McDonough [23] review study on the application of AM in the development of heat transfer devices.

From the above literature on the development of HXs, it is evident that additively manufactured HXs are used to develop novel HXs that offer the potential for higher efficiency. Although AM provides an opportunity to create novel geometries, it has some limitations, such as slow production speed, low print quality, support removal, and microstructure changes [24]. Moreover, little is known about these challenges that arise when trying to benefit from the advantages of AM fabricated parts. Therefore, the thermal performance of additive manufactured HXs requires further investigation to justify AM to set the benchmark for high-efficiency HXs with novel geometries. Furthermore, direct metal printing (DMP), a relatively new commercial metal AM technology, and the application of DMP in the production of HXs has been limited to date. 
Table 1. Recent published studies on additively fabricated heat exchangers (HXs).

\begin{tabular}{|c|c|c|c|c|c|c|c|c|}
\hline HX Type & Image & Material & $\begin{array}{c}\text { AM } \\
\text { Technology }\end{array}$ & \multicolumn{4}{|c|}{ Main Outcomes } & Ref. \\
\hline Air-cooled HX & & $\begin{array}{l}\text { Aluminium-silicon } \\
\text { pre-alloyed eutectic } \\
\text { material (AlSi12) }\end{array}$ & $\begin{array}{l}\text { Additive layer } \\
\text { manufacturing } \\
\quad(\text { ALM) }\end{array}$ & \multicolumn{4}{|c|}{ 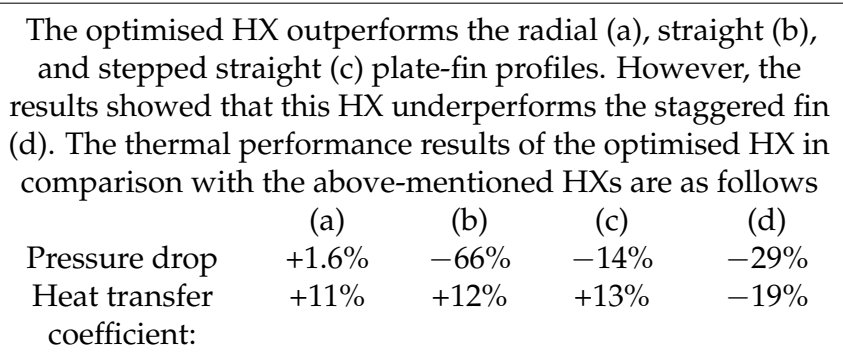 } & $\begin{array}{c}\text { Dedeet et al. } \\
{[13]}\end{array}$ \\
\hline Air-cooled HX & & $\begin{array}{l}\text { Stainless-steel (SS17-4) } \\
\text { Titanium alloy (Ti6Al4V) } \\
\text { Aluminium alloy } \\
\text { (AlSi10Mg) }\end{array}$ & DMLS & \multicolumn{4}{|c|}{$\begin{array}{l}\text { The thermal performance of the manifold-HX compared to } \\
\text { the wavy fin and plain plate-fin HXs was improved by } 30 \% \\
\text { and } 40 \% \text {, respectively. }\end{array}$} & [14] \\
\hline Water-cooled HX & & Stainless-steel (SS17-4) & DMLS & $\begin{array}{r}\text { The heat tran } \\
\text { consequently, } \mathrm{t} \\
\text { by } 40 \% \text { co }\end{array}$ & $\begin{array}{l}\text { r area of } \\
\text { overall } h \\
\text { ared to }\end{array}$ & $\begin{array}{l}\text { is } \mathrm{HX} \text { in } \\
\text { t transfe } \\
\text { origina }\end{array}$ & $\begin{array}{l}\text { eased by } 18 \% \text {, and } \\
\text { coefficient increased } \\
\text { ound tube HX. }\end{array}$ & [15] \\
\hline
\end{tabular}


Table 1. Cont.

\begin{tabular}{|c|c|c|c|c|c|}
\hline HX Type & Image & Material & $\begin{array}{c}\text { AM } \\
\text { Technology }\end{array}$ & Main Outcomes & Ref. \\
\hline Air-cooled HX & & Aluminium 6061 & SLM & $\begin{array}{c}\text { The pressure drop of this heat exchanger was } 50 \% \text { lower } \\
\text { than that of the HX with pin fin arrays. Moreover, the heat } \\
\text { transfer surface area of this AM-HX was greater than the } \\
\text { traditional HX and thus the heat transfer } \\
\text { coefficient increased. }\end{array}$ & [7] \\
\hline Air-cooled HX & & Stainless Steel 316L & SLM & $\begin{array}{c}\text { The thermal performance of the novel honeycomb-core HX } \\
\text { increased by } 17 \% \text { compared to the traditional } \\
\text { honeycomb HX. }\end{array}$ & [16] \\
\hline
\end{tabular}


In this study, three HXs were designed to investigate the effect of the profile, mass, and surface area on thermal performance (see Table 2). The HXs were manufactured with two different systems-conventional and AM. The milling machining process was used to conventionally manufacture the HXs and DMP to fabricate additively the same geometry HXs. In addition, an experimental test was designed to experimentally evaluate and compare the thermal performance of these three different HXs and their manufacturing technique. For simplicity, the HX with the rectangular profile is referred to HX1, the HX with the triangular profile is referred to HX2, the HX with National Advisory Committee for Aeronautics (NACA) airfoil profile is referred to HX3.

Table 2. Characteristics of test samples.

\begin{tabular}{|c|c|c|c|c|c|}
\hline Test Sample & $\begin{array}{l}\text { HX Surface Area/ } \\
\text { HX Volume }\left(\mathrm{mm}^{-1}\right)\end{array}$ & $\begin{array}{c}\text { Fin and Base Contact } \\
\text { Surface Area (mm) }\end{array}$ & $\begin{array}{c}\text { Heat Transfer Surface } \\
\text { Area }\left(\mathrm{mm}^{2}\right)\end{array}$ & Mass (gram) & $\begin{array}{c}\text { Surface Roughness } \\
\left(\mu \mathbf{m}^{\circ}\right)\end{array}$ \\
\hline CM-HX-Rectangular profile & 0.32 & 500.00 & $7.90 \times 10^{3}$ & 275.80 & 0.23 \\
\hline AM-HX-Rectangular profile & 0.32 & 500.00 & $7.90 \times 10^{3}$ & 266.60 & 5.08 \\
\hline $\mathrm{CM}-\mathrm{HX}$-Triangular profile & 0.41 & 500.00 & $7.08 \times 10^{3}$ & 200.48 & 0.36 \\
\hline AM-HX-Triangular profile & 0.41 & 500.00 & $7.08 \times 10^{3}$ & 194.50 & 4.72 \\
\hline CM-HX-NACA profile & 0.44 & 257.07 & $7.13 \times 10^{3}$ & 193.90 & 0.56 \\
\hline AM-HX-NACA profile & 0.44 & 257.07 & $7.13 \times 10^{3}$ & 182.90 & 4.42 \\
\hline
\end{tabular}

\section{Direct Metal Printing (DMP)}

DMP is an AM process, one of the PBF technologies, used to fabricate metallic parts in layers. In this technology, a powerful fibre laser with high energy intensity is used to quickly and fully melt the metal powder so that the new layer is properly attached to the previous layer. In this process, a shielding gas, such as argon, is used to prevent oxidation. As shown in Figure 1, a DMP system includes a layer deposition mechanism that creates powder layers, a power source, an optical system, a light sensor set, and a build platform $[25,26]$. To monitor heat, some DMP machines employ temperature sensors, such as thermocouples, or light sensors, such as photodiodes and digital cameras [25,27]. In this method, once a powder layer is printed, the build platform is lowered, and the deposition mechanism creates a new layer of metal powder. The laser beam is guided by the optical system and selectively and fully melts the powder to fuse with the previous layer. This process is repeated until the desired object is fully printed. To avoid oxidation during the melting process, an inert atmosphere of argon is maintained within the build chamber. The DMP technology has been featured in the studies of Moussaoui et al. [28] and Bisht et al. [25], in which porosity levels, microstructure, and mechanical properties such as tensile strength and surface roughness were studied for Inconel 718 and Ti-6Al-4V. Since the thermal performance of HXs may be negatively affected by differing material properties of AM-HXs [8], in this study, DMP was used to fabricate the consistent and homogenous HXs.

The current paper is organised as follows: Section 2 describes the experimental setup including HX designs and test procedures, Section 3 presents performance criteria and relevant mathematical models, Section 4 presents and discusses the experimental results, and Section 5 provides conclusions and discusses future research. 


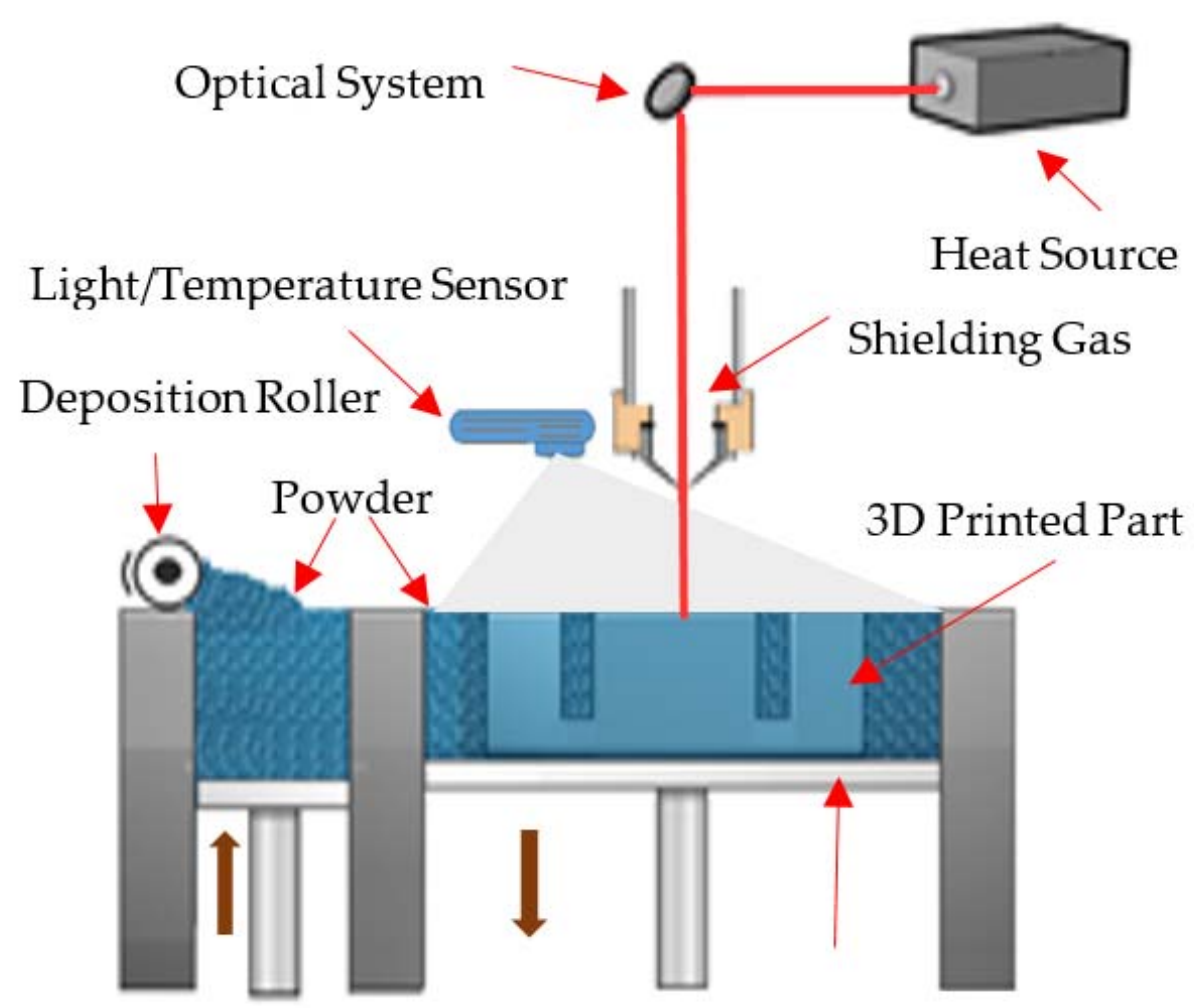

Build Platform

Figure 1. Schematic of the direct metal printing (DMP) mechanism.

\section{Experimental Setup}

\subsection{HX Design and Manufacturing}

Three HX fins were manufactured from stainless steel 316L, one of the commonly used materials in the production of HXs, and machined using a CNC machine. The same HX geometries were made of the same material, however, using DMP 3D printing technology. For simplicity, in the following sections, the conventionally and additively manufactured $\mathrm{HXs}$ are referred to as CM- and AM-HXs, respectively. According to the hotplate and wind tunnel's size, the overall dimensions of these HXs were considered as follows: width $50 \mathrm{~mm}$, length $50 \mathrm{~mm}$, and height $50 \mathrm{~mm}$. The characteristics of these HXs are given in Table 2. As shown in Figure 2, the fins include rectangular, triangular, and NACA profiles. A rectangular-style fin is commonly used in the design of HXs, such as automotive cooling fins [29], electronic equipment [30], and gas turbines [30]. Therefore, an HX with a rectangular profile was used for benchmarking in this research. Another fin used in this study is the triangular profile, which has $27 \%$ less mass than the rectangular HX, while the base contact area remains the same and the heat transfer surface area is reduced by $10 \%$. Moreover, the surface area to volume ratio of this $\mathrm{HX}$ is $28 \%$ greater than the rectangular profile. In addition to these two profiles, the NACA profile was designed based on the NACA 63-015 geometric details suggested by [31] and scaled to meet the size limitations of the other HX fins being tested. This NACA geometry allows for superior aerodynamic characteristics, namely, reduced aerodynamic drag. Furthermore, this profile provides extensive laminar boundary layers at large values of the Reynolds number. According to Ho et al. [32], the NACA profile reduces the airflow resistance and pressure drops; however, it may be detrimental to the thermal performance, such as in the heat transfer coefficient and the Nusselt number through the formation of vortices in the air foil, which induces fluid mixing. 


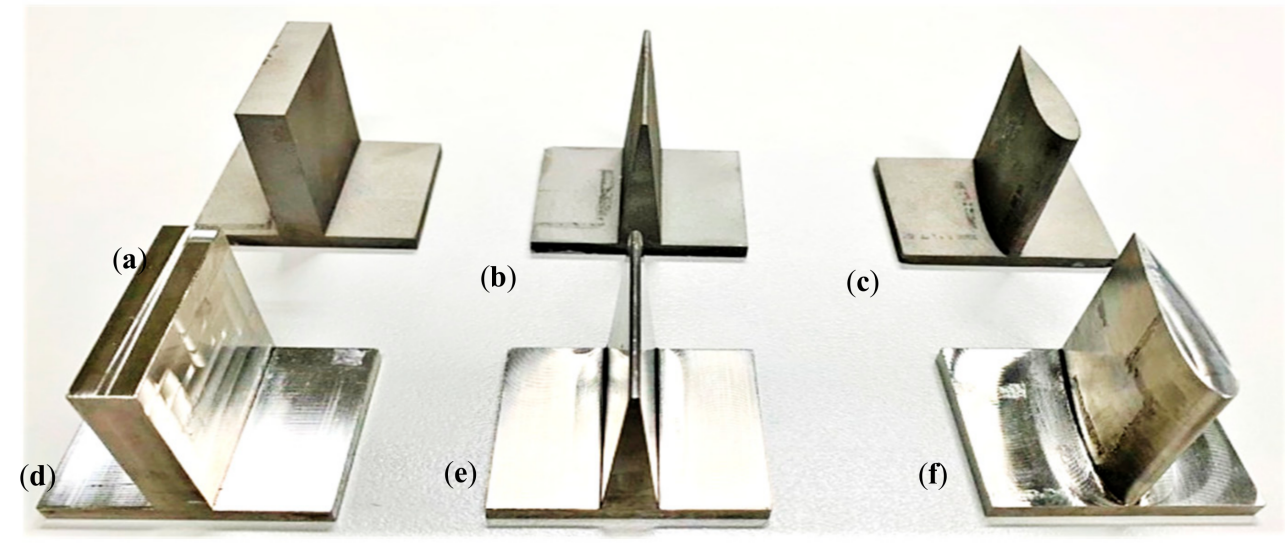

Figure 2. Test samples (a) AM-HX1; (b) AM-HX2; (c) AM-HX3; (d) CM-HX1; (e) CM-HX2; (f) CM-HX3.

In this study, an Okuma CNC Mill 5 Axis Model GENOS M460V-5AX (Okuma Inc., Oguchi-cho, Niwa-gun, Japan) was used for machining the stainless steel $316 \mathrm{CM}-\mathrm{HXs}$, and a Prox-x DMP 320 printer (3D Systems Inc., South Carolina, SC, USA) was used for printing stainless steel 316L AM-HXs. This equipment has exchangeable manufacturing modules to provide rapid material replenishment. Furthermore, the Prox-x DMP 320 tolerances for the high-resolution option in stainless steel 316L was $+/-0.15 \mathrm{~mm}$ over a $100 \mathrm{~mm}$ distance, and the thickness of layers was $30 \mu \mathrm{m}$. The following sections describe the test procedure and discuss the thermal efficiency results of the different HX profiles. In this study, the thermal performance of CM-HXs will be compared to the AM-HXs with the same profiles by using the thermal performance criteria explained in Section 3.

The microstructure images of the HXs were taken to evaluate the quality of the fabricated HXs using the LEICA M80 optical microscope (LEICA Inc., Germany), and the surface roughness of samples was measured using the TR200 surface roughness tester type (Electrometric Equipment Inc., Oakland, CA, USA).

\subsection{Test Procedure}

An experimental test rig was designed and manufactured to conduct the experimental studies and evaluate the thermal performance of the HXs. Figure $3 \mathrm{a}$,b shows the test rig's schematic and physical arrangement, respectively. The test rig consists of a small-scale open-channel wind tunnel that includes a rectangular test section, thermal and pressure sensors, velocimeter, copper block, hot-plate heater, data logger, and computer. The HX input temperature was controlled using a heater with a $136 \times 136 \mathrm{~mm}^{2}$ hot plate. This heat was funnelled into the smaller $\left(50 \times 50 \mathrm{~mm}^{2}\right) \mathrm{HX}$ base using a copper block that was uniformly heated using the heater by thermal paste. The copper block was placed outside the test section, and it was insulated using adhesive thermal insulation mats. As shown in Figure 3, the designed HXs were clamped to the copper block and placed in the straighter to help reduce the lateral velocity components, which are created by swirling movements, and consequently reduces the turbulence of the incoming airflow. The airflow rate was controlled using a combination of a velocimeter (Omega Inc., Norwalk, CA, USA) in conjunction with a variable-speed controller. The fluid (air) was drawn-in by a blower and through a honeycomb flow straighter with regular square cells (Tecquipment Inc., Nottingham, UK). The flow straightener helps reduce the lateral velocity components created by swirling movements, consequently reducing the turbulence of the incoming airflow. The airflow rate was controlled using a combination of a velocimeter in conjunction with a variable-speed controller (Tecquipment Inc., Nottingham, UK). 


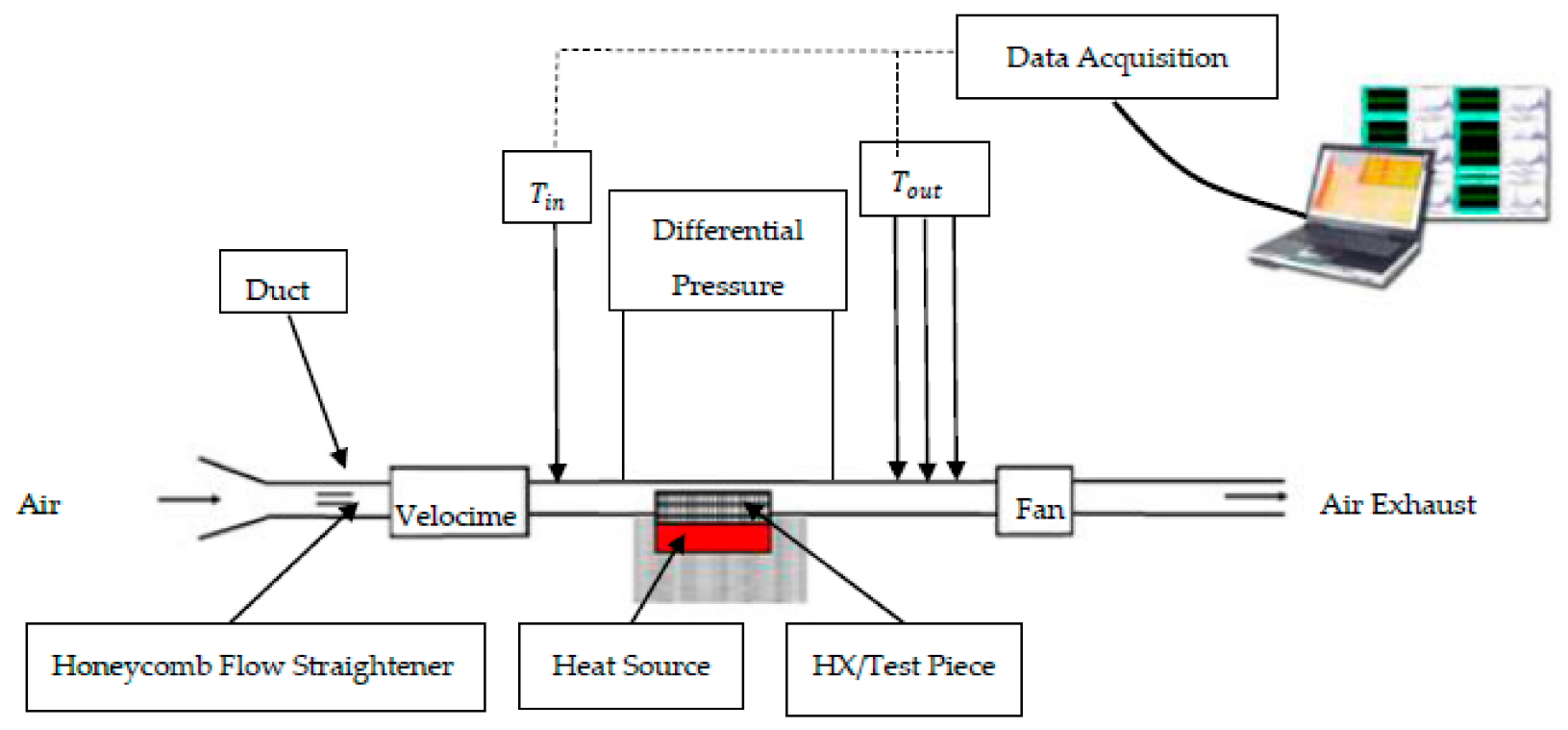

(a)

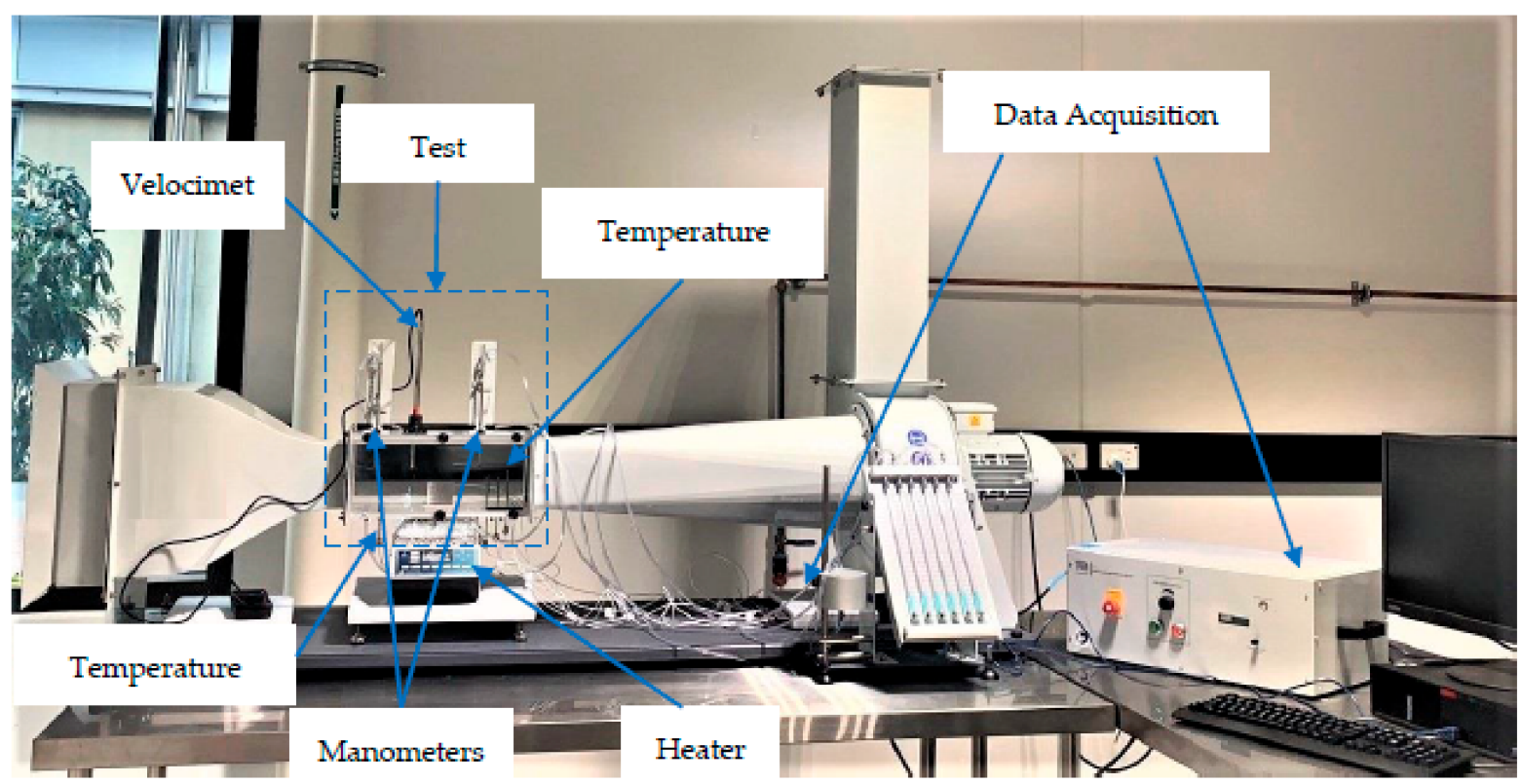

(b)

Figure 3. Test rig: (a) schematic and (b) experimental.

The location of the temperature sensors, manometers, and velocimeter is shown in Figure 3. In this research, surface and probe resistance thermometers (RTDs) (Omega Inc., Norwalk, CA, USA) were used to measure temperature with high accuracy. An RTD probe sensor was used to measure the inlet temperature, and three RTD probe sensors were placed along the test section outlet for measuring output temperatures. The height of these sensors was adjusted with incremental increases to capture the outlet temperature distribution, and the average of the results was measured as $\mathrm{T}_{\text {out }}$. According to Wong et al. [3], and Ravi and Saini [33], $\mathrm{T}_{\mathrm{am}}$ is the bulk mean temperature of the air and the average inlet and outlet temperatures were defined as $T_{\text {in }}$ and $T_{\text {out }}$, respectively. The HX temperature was taken using three RTD surface temperature sensors, placed at different locations on the HX's fin surface, to check the surface temperature distribution and average surface temperature. Before the experiments, these RTD sensors were calibrated using a digital 
thermometer (Omega Inc., Norwalk, CA, USA), and the results showed that not much calibration was required as the data acquisition modules were specifically designed for these RTD sensors. Two OM-CP-OCTPRO data acquisition modules collected the readings of these sensors. It should be noted that different sensor holders and/or clamps were designed and 3D-printed using the fused deposition modelling (FDM) technique. These sensor holders were manufactured from polylactic acid (PLA) using the Raise3D Pro2 (Raise3D Inc., Irvine, CA, USA) and Zortrax M200 printers (Zortrax Inc., Olsztyn, Poland).

Heat loss due to radiation was minimised in the experimental study by insulating the heater and copper block. Additionally, it was assumed that the radiative heat losses are the same for all HXs. In addition, the HX was placed in a rectangular test section. For similar experimental investigations, Tahat et al. [34] and Jubran and AI-Salaymeh [35] concluded that radiative heat losses are negligible. Accordingly, in this study, the heat loss due to radiation was ignored in calculations.

The following criteria were used to evaluate the HX performance: convective heat transfer coefficient, Nusselt number, thermal fluid dynamic behaviour, and friction factor. The HX was heated, and then the temperatures and flowrate were recorded at one-second intervals, and 300 samples were taken to achieve these. This approach was repeated three times and then the average temperatures, pressures, and flow rates were measured to calculate the heat transfer coefficient, Nusselt number, thermal fluid dynamic behaviour, and the friction factor. According to the heater settings, the temperature was set to $30{ }^{\circ} \mathrm{C}$, $40{ }^{\circ} \mathrm{C}$, and $50^{\circ} \mathrm{C}$, after which the experimental tests were conducted. However, this paper presents the tests' results at $50{ }^{\circ} \mathrm{C}$, as more precise results were achieved due to the greater heat transfer. The friction factor measurements were conducted using four pressure manometers placed at the test section's inlet and outlet of the test section. The friction factor test was carried out when the HX was heated to evaluate the effects of temperature on the fluid properties. Then, the airflow rate and inlet and outlet pressures were recorded three times for each test, and the average of the results was taken.

\section{Thermal Performance Criteria}

To evaluate the thermal performance of the different heat exchangers, the following criteria were used. These parameters have been employed for evaluating the thermal performance and air pressure drop of HXs.

- Convective heat transfer coefficient;

- Nusselt number;

- Thermal fluid dynamic performance;

- Friction factor.

\subsection{Convective Heat Transfer Coefficient}

The heat transfer coefficient $(\mathrm{h})$, also known as the film coefficient, is a quantitative characteristic, which determines the rate of heat transmission over a resistant object. The convective heat transfer coefficient $(\mathrm{h})$ is the ratio between the heat flux and the temperature difference of the HX wall and can be computed as below [33].

$$
\mathrm{h}=\frac{\dot{\mathrm{m}} \mathrm{c}_{\mathrm{p}} \mathrm{t}_{\mathrm{HX}}}{\mathrm{A}_{\mathrm{hx}}}
$$

The HX temperature coefficient can be calculated as below.

$$
\mathrm{t}_{\mathrm{HX}}=\frac{\mathrm{T}_{\mathrm{out}}-\mathrm{T}_{\text {in }}}{\mathrm{T}_{\mathrm{s}}-\mathrm{T}_{\mathrm{am}}}
$$

where $\mathrm{T}_{\mathrm{s}}$ was defined by taking the average of $\mathrm{HX}$ surface temperature at different locations, and $\mathrm{T}_{\mathrm{am}}$ was defined by taking the average of inlet and outlet temperatures. In addition, the specific heat capacity of air was considered $1.006 \times 10^{3}\left(\mathrm{~J} \cdot \mathrm{kg}^{-1} \cdot \mathrm{K}^{-1}\right)$. 
As shown below, the fluid mass flowrate (m) is the function of the density of the flowing air, airflow rate, and the cross-sectional vector area of the test section.

$$
\dot{\mathrm{m}}=\rho \mathrm{VA}
$$

It should be noted that the air density changes with the temperature. Therefore, the below equation was used to calculate the air density at the given temperature [36].

$$
\rho=\frac{P}{R\left(T_{a m}+273.15\right)}
$$

where the specific air constant $(\mathrm{R})$ was $287.05\left(\mathrm{JKg}^{-1} \mathrm{~K}^{-1}\right)$, and the air atmospheric temperature was $101.325 \times 10^{3} \mathrm{~Pa}$.

\subsection{Nusselt Number}

Nusselt number $(\mathrm{Nu})$ is a dimensionless number and defines the ratio of convective to conductive heat transfer across a boundary in a fluid. Increasing this number corresponds to more efficient convection [33]. The Nusselt number is a function of the Reynolds number, the ratio between the inertial forces in a fluid and the viscous forces, and the Prandtl number, the ratio of momentum diffusivity to thermal diffusivity [37]. Therefore, the following equation was used to compute the Nusselt number at the given temperature [33].

$$
\mathrm{Nu}=\frac{\mathrm{h} \mathrm{D}_{\mathrm{h}}}{\lambda}
$$

where is the hydraulic diameter of the rectangular cross section and can be computed as

$$
\mathrm{D}_{\mathrm{h}}=\frac{4 \mathrm{WH}}{2(\mathrm{H}+\mathrm{W})}
$$

The Reynolds number was calculated to show the ratio of inertial forces to viscous forces within the forced air. To calculate the Reynolds number, the below equation was used.

$$
\operatorname{Re}=\frac{\rho \mathrm{VD}_{\mathrm{h}}}{\mathrm{V}}
$$

Air viscosity increases with temperature; thus, the Sutherland equation was used to estimate the kinematic viscosity [38].

$$
\mathrm{v}=\frac{\mathrm{b}\left(\mathrm{T}_{\mathrm{am}}+273.15\right)^{3 / 2}}{\left(\mathrm{~T}_{\mathrm{am}}+273.15\right)+\mathrm{S}}
$$

where $\mathrm{b}$ and $\mathrm{S}$ are constant, and for air, and these values are equal to $1.716 \times 10^{-5}\left(\mathrm{~kg} / \mathrm{m} \cdot \mathrm{s} \cdot \mathrm{K}^{1 / 2}\right)$ and $110.4(\mathrm{~K})$, respectively.

\subsection{Thermal Fluid Dynamic Performance}

Fluid dynamic performance defines the flow behaviour of fluids in motion. The magnitude of this factor corresponds to the efficiency of HXs. The thermal fluid dynamic performance was applied to remove variations in results and clearly represent which of the HXs are able to exchange the most heat at different airflow rates. This removes the thermal performance measure favoured HXs with a greater surface area. To achieve the required formula, the heat transfer coefficient (see Equation (1)) was normalised by multiplying the heat transfer coefficient by the HX surface area. Therefore, the below formula was used.

$$
\mathrm{h}_{\mathrm{FD}}=\dot{\mathrm{m}} \mathrm{c}_{\mathrm{p}} \mathrm{t}_{\mathrm{HX}}
$$




\subsection{Friction Factor}

The dimensionless representation of the pressure drop across the HX was defined by the friction factor $\mathrm{f}$, and equated as follows [39,40]. This equation is known as Darcy's formula.

$$
\mathrm{f}=\frac{2 \Delta \mathrm{PD}}{\rho L V^{2}}
$$

\section{Results and Discussions}

In this section, the experimental results of the six stainless steel 316L HXs are presented, and the thermal performances of these HXs are compared and discussed. As discussed in Section 3, convective heat transfer coefficient, Nusselt number, fluid dynamic performance, and friction factor are used for evaluating the thermal performance of HXs. The thermal performance of test samples is shown in Figures 4-8.
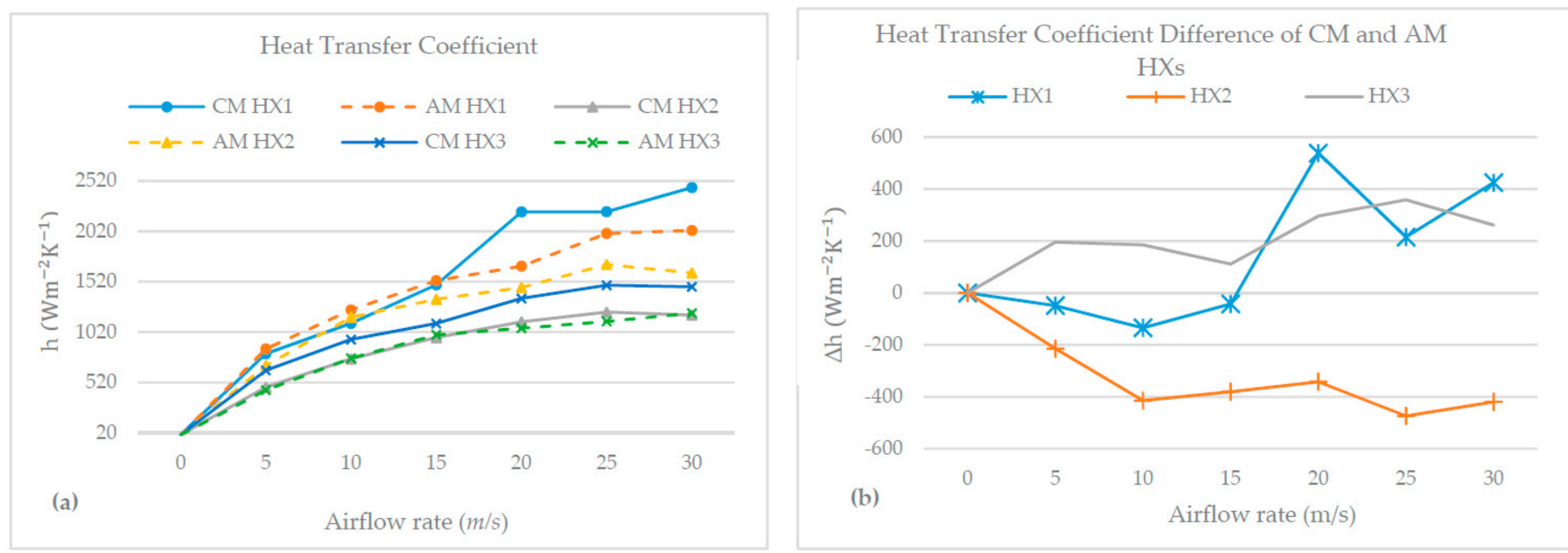

Figure 4. Experimental results when the heater temperature was $50{ }^{\circ} \mathrm{C}$ : (a) convective heat transfer coefficient and (b) convective heat transfer coefficient difference between CM- and AM-HXs.
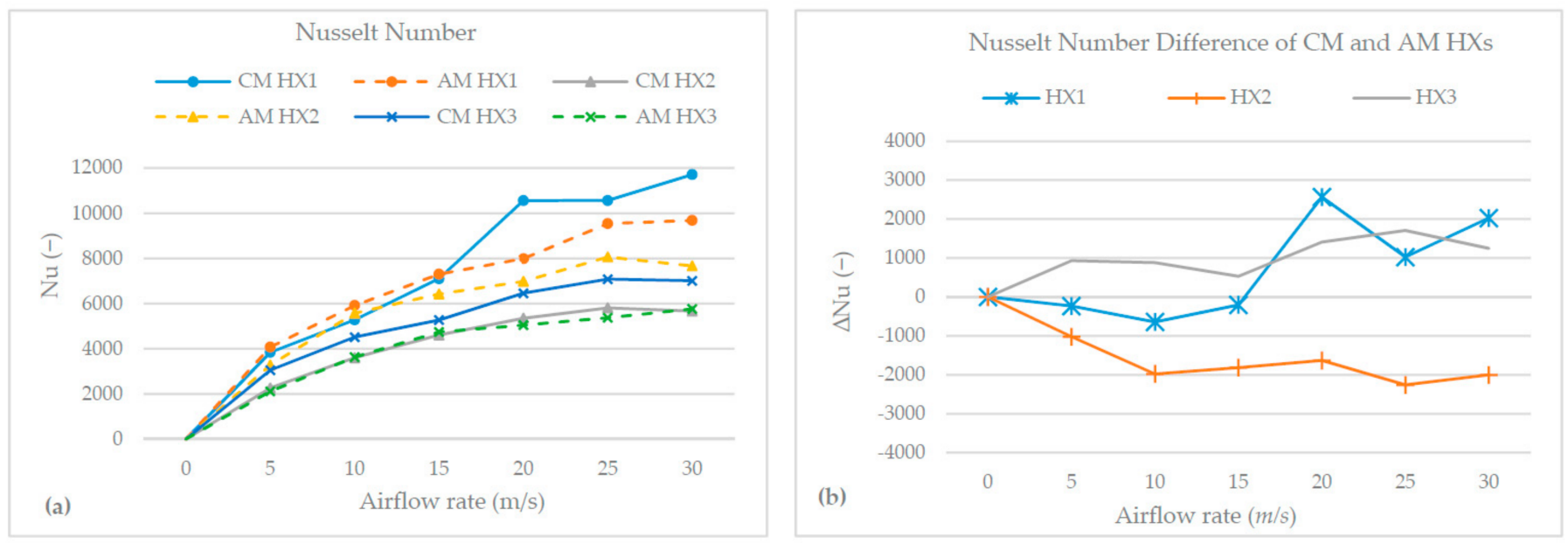

Figure 5. Experimental results when the heater temperature was $50{ }^{\circ} \mathrm{C}$ : (a) Nusselt number and (b) Nusselt number difference between the CM- and AM-HXs. 


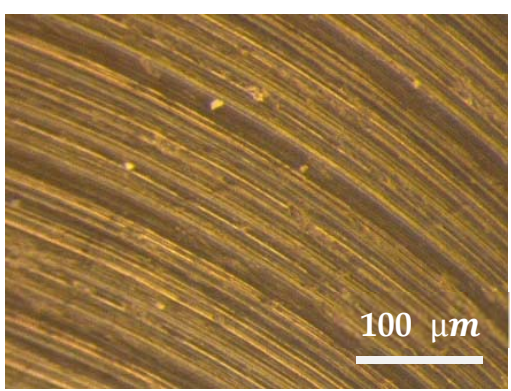

(a)

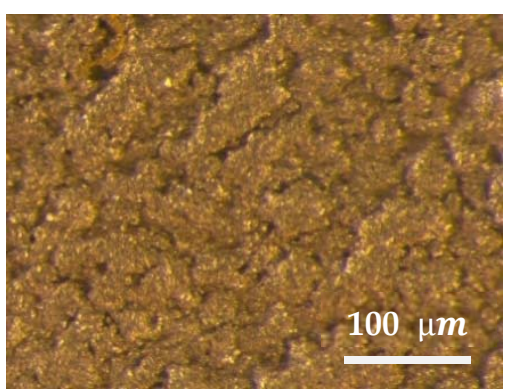

(d)

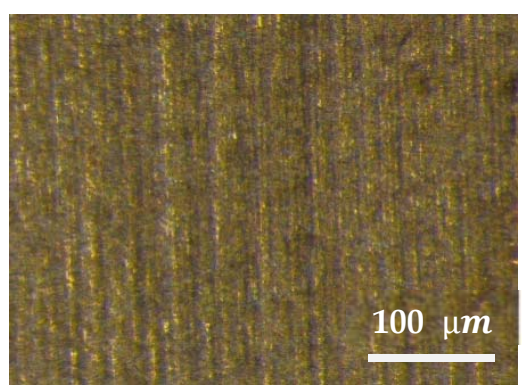

(b)

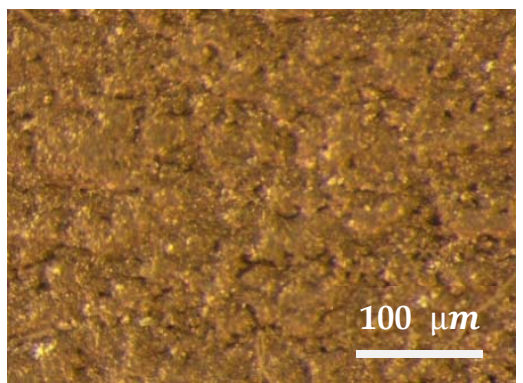

(e)

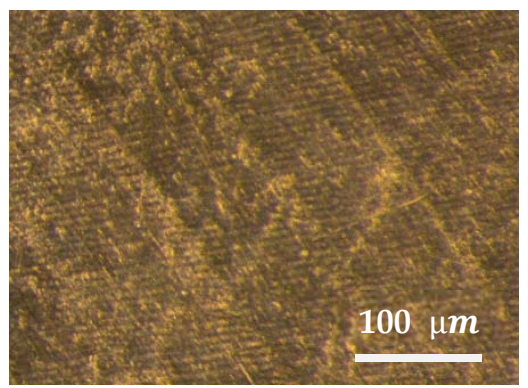

(c)

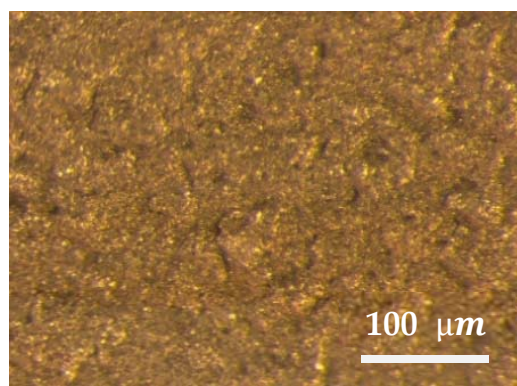

(f)

Figure 6. Microstructure structure of the additively and conventionally manufactured HXs: (a) CM-HX1 $\mathrm{R}_{\mathrm{a}}=0.23 \mu \mathrm{m}$; (b) CM-HX2 $\mathrm{R}_{\mathrm{a}}=0.36 \mu \mathrm{m}$; (c) CM-HX3 $\mathrm{R}_{\mathrm{a}}=0.56 \mu \mathrm{m}$; (d) AM-HX1 $\mathrm{R}_{\mathrm{a}}=5.08 \mu \mathrm{m}$; (e) AM-HX2 $\mathrm{R}_{\mathrm{a}}=4.72 \mu \mathrm{m}$; and (f) AM-HX3 $\mathrm{R}_{\mathrm{a}}=4.42 \mu \mathrm{m}$.

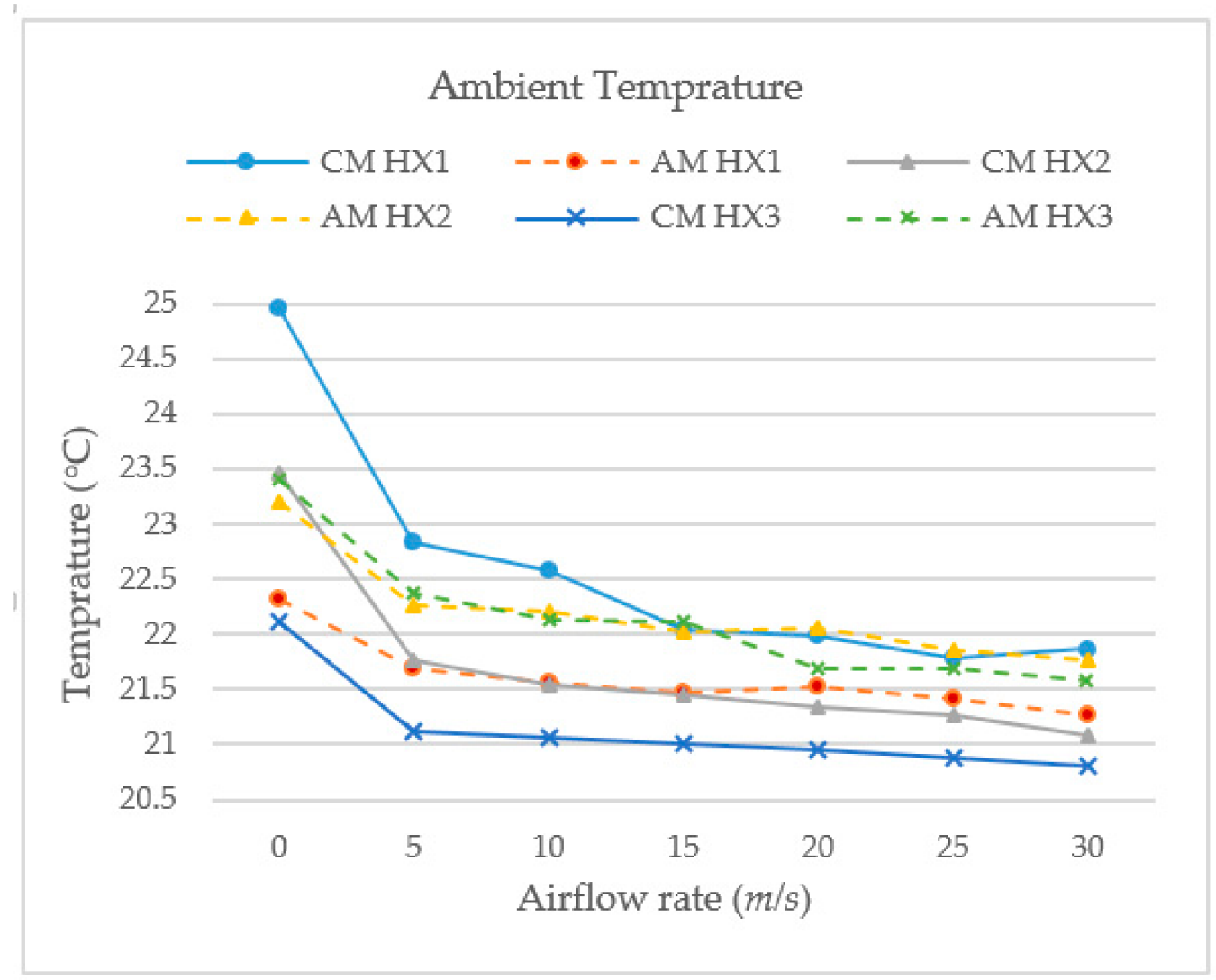

Figure 7. HX ambient temperature for different $\mathrm{HX}$ s when the heater temperature was $50{ }^{\circ} \mathrm{C}$. 


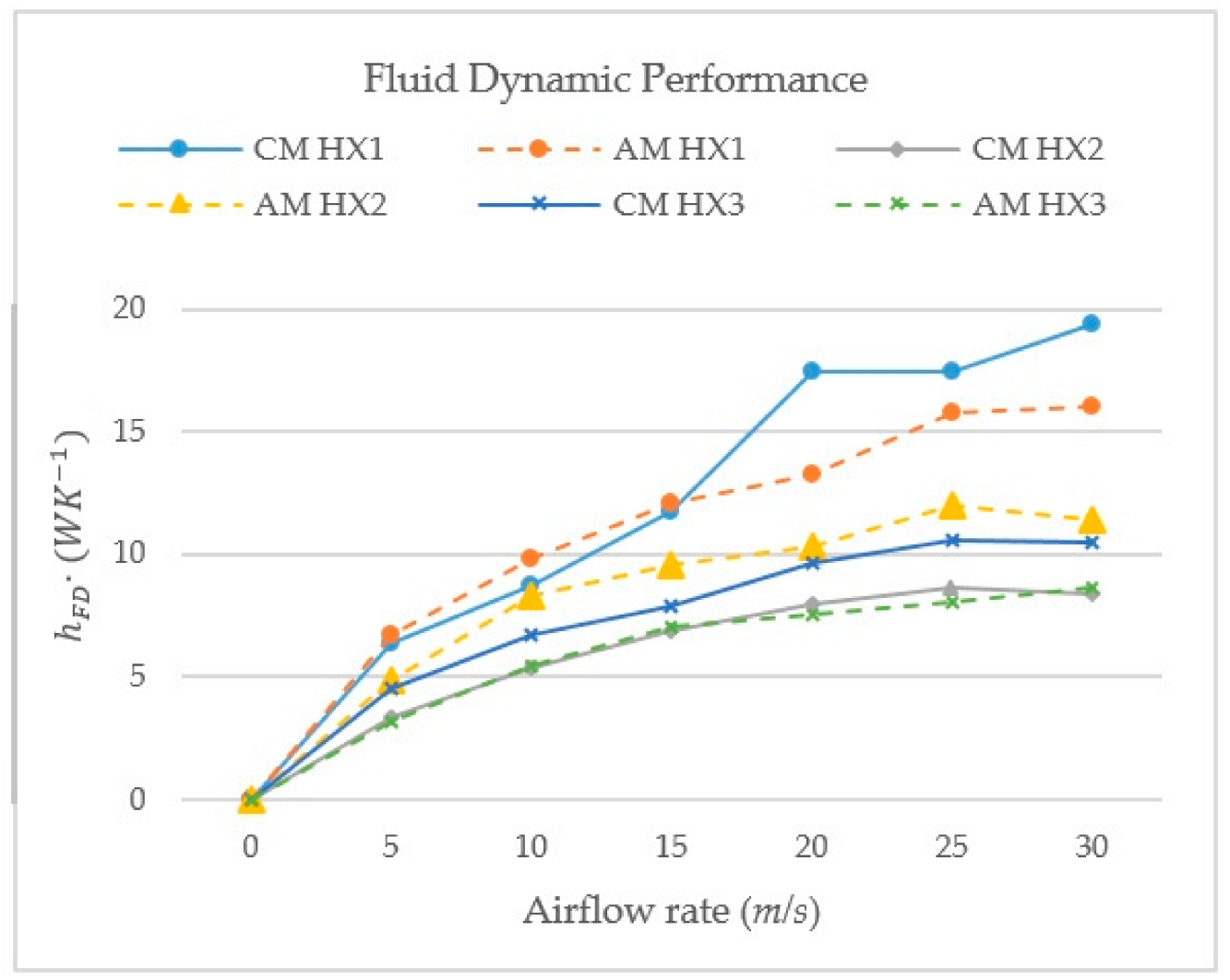

Figure 8. Experimental thermal fluid dynamic performance of HXs when the heater temperature was $50^{\circ} \mathrm{C}$.

\subsection{Convective Heat Transfer Coefficient and Nusselt Number}

The convective heat transfer coefficient and Nusselt number of all HXs are presented in Figures 6a and 6a, respectively. For these thermal characteristics, it is considered that 'the larger, the better'. As expected, it can be seen that the overall thermal performance of all HXs was boosted by increasing the airflow rate. As shown in Equation (1), the mass flow rate is one of the main contributors to the heat transfer coefficient. By increasing the mass flow rate, this coefficient increases and consequently boosts the heat transfer efficiency. In general, printed and machined rectangular fins, i.e., CM-HX1 and AM-HX1, provide more thermal effectiveness than other studied fins due to the high heat transfer surface area. As shown in Table 2, the HX with a triangular profile (HX2) has the lowest heat transfer surface area. As the surface area is one of the key contributors to the heat transfer coefficient and the Nusselt number, the $\mathrm{CM}-\mathrm{HX} 2$ has the smallest values for these thermal characteristics. Although the heat transfer surface area of the HX3 is $0.6 \%$ less than that of the HX2, it can be seen that the heat transfer coefficient and the Nusselt number of AM-HX3 are similar to the CM-HX2. Indeed, the material properties and the surface roughness of this $\mathrm{AM}-\mathrm{HX}$ were affected by the manufacturing process and consequently reduced the thermal performance. Therefore, it can be observed that the thermal behaviour of the printed and machined HXs with the same geometry is not the same at different airflow rates. Overall, it can be seen that the heat transfer coefficient and Nusselt number differences between printed and machined HXs with the same geometry increases at higher airflow rates Figures $4 \mathrm{~b}$ and $5 \mathrm{~b}$ ). This is due to the fact that the heat transfer coefficient and the Nusselt number are functions of the airflow rate. The slight fluctuating behaviour is due to the inlet and outlet temperatures that are affected by the formed inlet vortices.

Figures 4 and 5 show that the thermal characteristics of the AM-HX1 are higher than the CM-HX1 when the airflow rate changes between 0 to $15 \mathrm{~m} / \mathrm{s}$; however, by increasing the airflow rate, the CM-HX1 transfers more heat than the AM. Figure 6 shows 
the microstructure of the investigated HXs and their surface roughness. It can be seen that the surface roughness of the AM-HX1 is $4.58 u \mathrm{~m}$ higher than the machined one. The surface roughness made by the DMP method enhances the convective heat transfer for low airflow rates.

In addition, the material properties allow the CM-HX1 to transfer more heat than the AM-HX1 and consequently increase the ambient temperature. The air viscosity, increases and does not allow the air to travel effectively through the HX, reducing the heat transfer efficiency, as shown in Figure 7. On the other hand, when the airflow rate exceeds $15 \mathrm{~m} / \mathrm{s}$, the heat transfer coefficient and Nusselt number of the CM-HX1 outperform the AM-HX1.

Ventola et al. [8] experimentally investigated the thermal performance of an additive manufactured rectangular fin, and they found that the surface roughness may be detrimental due to the presence of porosity and affect the thermal conductivity negatively. This is also applicable to the HX with NACA profile (HX3), and it is clear that the high surface roughness negatively affects the thermal performance of this HX. However, this is not the case for the HX with the triangular profile. Since the surface roughness of the AM-HX2 is greater than that of the CM-HX2 (see Table 2 and Figure 6), it provides a higher heat transfer coefficient and Nusselt number than the AM-HX2 at different speeds. Moreover, Figures $4 \mathrm{a}$ and $5 \mathrm{a}$ show that the $\mathrm{CM}-\mathrm{HX} 3$ provides higher thermal performance than the $\mathrm{CM}-\mathrm{HX} 2$; however, the HX3 profile has a higher heat transfer area than the HX2 profile. This is because surface roughness increases the heat transfer surface area and consequently enhances the heat transfer conductivity in turbulent thermal convection. It also includes turbulent boundary layer flows, which improve the thermal performance.

From the above, it can be concluded that the manufacturing method of HXs causes a considerable effect on the thermal performance of HXs. In addition, the distribution and number of internal voids and cracks, which might be created during and after the AM processes, affect the thermal performance of HXs. Furthermore, the difference in the thermal performance of these HXs is expected because the airflow over each fin is different due to the difference in fin profiles and requires further investigation in Section 4.2.

\subsection{Thermal Fluid Dynamic Performance}

The above sections focused on the thermal performance of dissimilar HXs and did not isolate the fluid dynamic performance effects of each HX. Therefore, the heat transfer coefficient was normalised as formulated in Equation (9) to represent how HXs transfer heat. According to Table 1, the heat transfer area of HX2 and HX3 was reduced by 10.3\% and $9.7 \%$, respectively, compared with HX1. In these modified formulas, the heat transfer area was removed from the heat transfer coefficient equation, and therefore, clear changes can be observed in Figure 7, compared to Figures 4 and 5.

Figure 8 shows that CM-HX1 and AM-HX1 both exchange more heat than the other HXs. However, AM-HX1 ranks once in terms of the amount of heat transferred during lower flowrates, i.e., when the airflow rate is lower than $15 \mathrm{~m} / \mathrm{s}$. In addition to the discussion presented in Section 4.1, the surface roughness of AM-HX1 enhances the convective heat transfer. It increases the air temperature differences, consequently changing the fluid density and improving the fluid motion, whereas, the surface roughness is less significant when the airflow rate exceeds $15 \mathrm{~m} / \mathrm{s}$. According to Equations (2) and (9), the thermal fluid dynamic performance is a function of the HX temperature coefficient. The results show that, with higher airflow speeds, the HX temperature coefficients of AM-HX1 are less than those of CM-HX1. For instance, when the airspeed is $20 \mathrm{~m} / \mathrm{s}$, the temperature coefficient of AM-HX1 is $25 \%$ less than that of CM-HX1. This is due to the fact that the existing porosity of AM-HX1 results in the reduction of the average surface temperature when airflow rates are higher.

Figure 8 also shows that the performance of $\mathrm{CM}-\mathrm{HX} 2$ and AM-HX3 is similar over the measured airflow rate range, although the heat transfer surface area of $\mathrm{CM}-\mathrm{HX} 2$ is slightly lower than that of AM-HX3. The surface area has less of an impact on the thermal performance than the porosity. Indeed, AM-HX3 is not a homogenous object, and 
the existing porosity in AM-HX3 has a negative effect on the thermal conductivity (see Figure 6). Figure 8 also shows that the $\mathrm{CM}-\mathrm{HX} 3$ heat transfer performance is greater than that of CM-HX2 and AM-HX3. This is because HX3 has a greater heat transfer area of CMHX3 than that of HX2, and it, therefore, transfers more heat. Moreover, the NACA profile of $\mathrm{CM}-\mathrm{HX} 3$ reduces the airflow resistance and enhances the heat exchange through the formation of vortices around the fin edge and consequently increases the airflow motion.

One other observation is that AM-HX2 dissipates more heat than CM-HX3. This is expected since the surface roughness of AM-HX2 is approximately $4.72 \mu \mathrm{m}$, whereas the surface roughness of $\mathrm{CM}-\mathrm{HX} 3$ is about $0.36 \mu \mathrm{m}$ (see Figure 6). The greater surface roughness of AM-HX2 disrupts the thermal boundary layers and tabulates the flow, thereby enhancing the heat exchange.

\subsection{Convective Friction Factor}

The friction factors of all HXs are presented in Figure 9. According to the findings of Wong et al. [3], the pressure drop is one of the essential parameters in evaluating the thermal performance of heat exchange devices. The pressure drop is considered 'the smaller, the better'. This critical parameter is used to determine how much fluid flow is available to transfer heat and perform the cooling process. In this study, the friction factor, which is a function of pressure drop, is used to consider this parameter. The friction factor of the HXs is shown in Figure 9a, and the difference in the friction factor of the machined and printed HXs is shown in Figure 9b. Figure 9a shows that generally, the friction factor of the HXs reduces by increasing the airflow rate, i.e., the pressure drop increases by increasing the airflow rate. This is because the friction factor is the inverse of the airflow rate (see Equation (10)). This figure shows that CM-HX1 has the most friction-factor difference over the measured airflow rates. In contrast, AM-HX3, CM-HX3, and $\mathrm{CM}-\mathrm{HX} 2$ have nearly the same friction factor at different airflow rates and outperform other HXs. According to Hans et al. [41], the friction factor is affected by the Reynolds number, the surface roughness, and the geometry. Since the HXs' Reynolds number over the measured airflow rate range is greater than 3000 , it is assumed that the airflow falls into a turbulent flow regime. Clearly, the friction factor is affected by the geometry of HXs and the surface roughness.
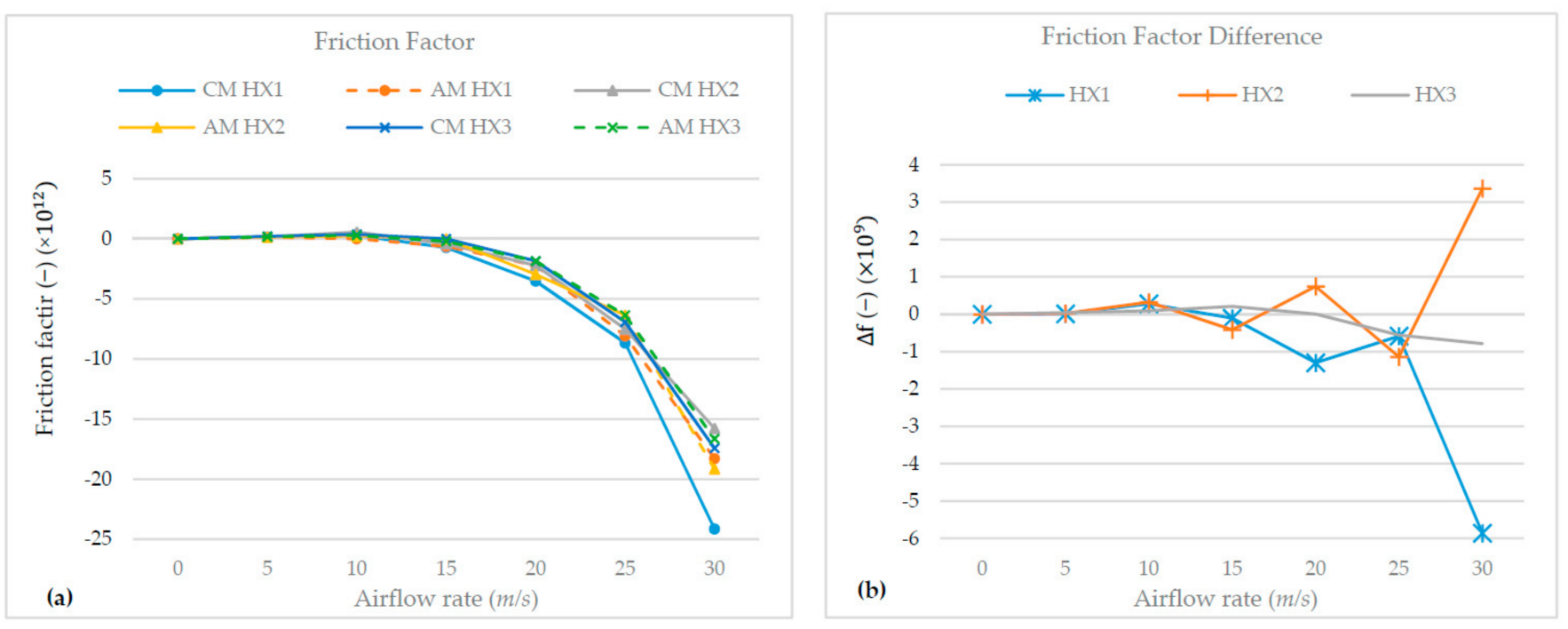

Figure 9. Experimental results when the heater temperature was $50{ }^{\circ} \mathrm{C}$ : (a) friction factor and (b) friction factor difference between $\mathrm{CM}$ - and AM-HXs.

Figure $9 \mathrm{~b}$ shows that the friction factor of $\mathrm{HX} 3$ is nearly constant, compared to the airflow rate. However, it slightly increases when the airflow rate exceeds $25 \mathrm{~m} / \mathrm{s}$ due to the increase in the Reynolds number, which causes the friction factor to be affected by 
the surface roughness of AM-HX3. In this figure, it can also be seen that the HX1 has a flocculated behaviour versus the airflow rate. The profile of the CM-HX1 and existing sharp edges increase the resistance forces to the airflow compared to other HXs; hence, this HX gives the maximum pressure drop at different studied airflow rates. However, due to the different manufacturing methods and the presence of the porosity in the microstructure of the AM-HXs, slight differences can be seen in the CM- and AM-HXs with the same geometry. Despite the geometric difference between HX2 and HX3, the heat transfer surface area of the HX2 and HX3 is nearly identical, i.e., the heat transfer surface area of the HX3 is only $0.7 \%$ greater than that of the HX2 (see Table 2). Therefore, the friction factor of these HXs is more or less the same; however, the surface roughness differences make slight changes in the friction factor results. Ventola et al. [8] studied the effect of surface roughness on the thermal performance of the AM rectangular cooling fins. However, they concluded that there is no universally accepted methodology to accurately relate the surface roughness to the pressure drop and thermal performance. The friction factor is affected by the ambient temperature, which is affected by the HX surface roughness, material properties, microstructure, and geometry. In addition, the ambient temperature affects the viscosity, and consequently, the pressure drops. The relationships between the thermal characteristics, turbulent flow, and surface roughness require further research.

\subsection{Overall Thermal Performance of HXs}

According to the literature, the HXs should be designed to enhance heat transfer characteristics, i.e., heat transfer coefficient, Nusselt number, and / or fluid dynamic performance at a minimum pressure drop. Therefore, in this study, the average of each thermal characteristic for the measured airflow rate range is calculated and compared to that of the CM-HX1. The results are presented as percentages to facilitate comparisons and interpretations in Table 3. Due to the presence of the porosity and the slight shrinkage in the size of the HXs, the masses of the AM-HXs were reduced by around $2-4 \%$ for different geometries, compared to the CM-HXs. It can be seen that the AM-HX3-the HX with the NACA profile fin-experienced the least pressure drop, which is $32 \%$ greater than that of the CM-HX1; however, this HX had the least thermal characteristics. This table demonstrates that the AM manufacturing process reduces the pressure drop of the HX3. Similar results can be observed for HX1 and HX2. Although the surface roughness of AM-HXs generates vortices and consequently enhances heat transfer and increases pressure drop, the reduction of sharp edges of the AM-HXs reduces the curvature of the airflow and therefore prevents more pressure drop. It is evident that in geometries with considerable aerodynamic characteristics, the pressure drop increment reduces. Table 3 presents the average of each characteristic, which is calculated and compared to CM-HX1, for the measured airflow rate range.

Table 3. Thermal performance of test samples compared to CM-HX1.

\begin{tabular}{cccccc}
\hline Test Sample & Mass (\%) & $\begin{array}{c}\text { Heat Transfer } \\
\text { Coefficient (\%) }\end{array}$ & $\begin{array}{c}\text { Nusselt Number } \\
\mathbf{( \% )}\end{array}$ & $\begin{array}{c}\text { Thermal Fluid } \\
\text { Dynamic } \\
\text { Performance (\%) }\end{array}$ & Friction Factor (\%) \\
\hline AM-HX1 -Rectangular profile & $-3 \%$ & $-10 \%$ & $-9 \%$ & $-9 \%$ & $-21 \%$ \\
CM-HX2 -Triangular profile & $-27 \%$ & $-44 \%$ & $-44 \%$ & $-50 \%$ & $-23 \%$ \\
AM-HX2 -Triangular profile & $-29 \%$ & $-23 \%$ & $-22 \%$ & $-30 \%$ & $-31 \%$ \\
CM-HX3-NACA profile & $-30 \%$ & $-32 \%$ & $-32 \%$ & $-38 \%$ & $-30 \%$ \\
AM-HX3 -NACA profile & $-34 \%$ & $-46 \%$ & $-46 \%$ & $-51 \%$ & $-32 \%$ \\
\hline
\end{tabular}

Table 3 also shows that the increased surface roughness in HX2 enhances the overall thermal characteristics, such as heat transfer coefficient, Nusselt number, and fluid dynamic behaviour. Indeed, the surface roughness generates vortices and separates boundary layers. This leads to higher temperature gradients near the HX walls and consequently more heat transfer. However, the surface roughness does not always enhance heat transfer and may 
trap airflow inside the cavities, leading to a much thicker thermal boundary layer. This result can be observed for HX1 and HX3, and clearly, the overall heat flux through these AM-HXs is reduced. For instance, the heat transfer coefficient of AM-HX1 and AM-HX3 is $10 \%$ and $20 \%$ less than that of CM-HX1 and CM-HX3, respectively.

\section{Conclusions and Future Perspectives}

Although AM provides flexibility to design novel HXs, the utilisation of AM in the fabrication of HXs is not currently accepted by industries. However, AM is rapidly advancing with new systems being developed. Therefore, further investigation is required to study new AM systems and unknown AM challenges of these technologies on specific applications such as heat exchange devices. In this paper, one of the recent advancements in AM, the DMP process, was introduced, and six HXs were manufactured using additive and conventional manufacturing processes-largely focusing on main characteristics such as surface roughness and shape; however, further investigation is required with the full potential of AM utilised, through complex HX shapes. In this study, an experimental test rig was designed and manufactured to investigate the thermal performance of the produced HXs experimentally using four thermal characteristics, namely, heat transfer coefficient, Nusselt number, thermal fluid dynamic performance, and friction factor. The mathematical model of these items was also presented in this paper. The experimental results of the $\mathrm{CM}-\mathrm{HX}$ s were compared to the AM-HXs, and the following were observed:

- The friction factor differences between AM- and CM-HXs with NACA, triangular, and rectangular profiles are $2 \%, 7 \%$, and $21 \%$, respectively;

- The AM-HX sample with the NACA profile fin provided the least pressure drop, which is $32 \%$ lower than that of the CM-HX sample with a rectangular profile;

- The heat transfer surface area of the HX3 with NACA profile was $0.6 \%$ less than that of the HX2 with a triangular profile, the heat transfer coefficient and the Nusselt number of AM-HX3 were similar to the CM-HX2. This is due to the fact that the material properties and the surface roughness of this AM-HX were affected by the manufacturing process and consequently reduced the thermal performance;

- The thermal performance of the rough surface of AM-HX with a triangular profile was about $21 \%$ greater on average than that of smooth HX with the same profile. However, the thermal performance of AM-HXs with rectangular and NACA profiles was about $10 \%$ and $14 \%$ lower than those of smooth HXs with the same profiles, respectively.

Therefore, the following conclusions were drawn from the observed experimental results:

- The thermal characteristics of the HXs appeared to be functions of the HX geometry, material microstructure, manufacturing process, and surface roughness. Therefore, more fundamental research is required to develop a methodology and/or mathematical model to relate these parameters to the thermal performance of HXs. Consequently, optimisation models are required to be developed to find the most effective of the above-mentioned parameters in maximising heat transfer and minimising the pressure drop;

- The roughness leads to the development of the vortices and boundary layers, which increase the temperature gradients near the $\mathrm{HX}$ walls and consequently improving thermal efficiency. It is noteworthy that the results showed that the roughness does not always provide a heat transfer enhancement and may negatively affect the thermal characteristics. When the airflow rates are low, the flow may be trapped inside the voids between the surface elements and consequently reduce overall heat flux through the HX. This can be evaluated by simulating artificial roughness and investigating how the flows are created and the thermal performance of HXs is affected. The optimum design of roughness heights and/or patterns is influenced by the HX material properties and proper selection of the AM process parameters, which require further study;

- In general, the higher surface roughness increases the pressure drop by increasing the shear stress near the wall of the HXs; however, the reduction of sharp edges in 
the AM-HXs results in reducing the curvature of the airflow and therefore reduces pressure loss;

- The AM-HXs will likely have more significant radiative losses than those conventionally manufactured due to their surface finish, further clouding the data analysis;

- The thermal conductivity is affected by porosity, which might be created during and after the AM processes. The proper selection of AM process parameters to minimise porosity is required to ensure reasonable thermal properties of HXs. These properties can be improved by further post-processing operations such as heat treatment;

- In addition to the above, designing for AM needs a complete understanding of the AM manufacturing processes' benefits and limitations. Furthermore, topology and shape optimisation studies are required to design high-efficiency HXs and calls for further investigation.

Author Contributions: Conceptualisation, A.V. and F.G.; methodology, A.V., F.G., and K.H.; validation, A.V.; formal analysis, A.V. and F.G.; investigation, A.V.; resources, A.V.; data curation, A.V.; writing—original draft preparation, A.V.; writing—review and editing, A.V. and F.G.; visualisation, A.V.; funding acquisition, A.V. All authors have read and agreed to the published version of the manuscript.

Funding: This study was supported by the Edith Cowan University (ECU) under Grant G1004423. In addition, the authors would like to thank for the financial support from the ECU School of Engineering.

Institutional Review Board Statement: Not applicable.

Informed Consent Statement: Not applicable.

Conflicts of Interest: The authors declare that there is no conflict of interest.

\section{Nomenclature}

A Test rig cross - section area $\left(\mathrm{m}^{2}\right)$

$A_{h x} \quad$ HX surface area $\left(\mathrm{m}^{2}\right)$

$b \quad$ Sutherland constant value $\left(\mathrm{kg} / \mathrm{m} \cdot \mathrm{s} \cdot \mathrm{K}^{1 / 2}\right)$

$c_{p} \quad$ Heat capacity of fluid $\left(\mathrm{J} \cdot \mathrm{kg}^{-1} \cdot{ }^{\circ} \mathrm{C}^{-1}\right)$

$D_{h} \quad$ Hydraulic diameter (m)

$f \quad$ Friction factor (-)

$H \quad$ Test section height (m)

$h \quad$ Thermal heat transfer coefficient $\left(\mathrm{W} \cdot \mathrm{m}^{-2} \cdot \mathrm{K}^{-1}\right)$

$h_{F D} \quad$ Fluid dynamic performance $\left(\mathrm{W} \cdot \mathrm{K}^{-1}\right)$

$L \quad$ HX length in flow direction (m)

m Air mass flowrate $\left(\mathrm{K} \cdot \mathrm{g} \cdot \mathrm{s}^{-1}\right)$

$\mathrm{Nu} \quad$ Nusselt Number (-)

$P \quad$ Atmospheric pressure $(\mathrm{Pa})$

$\Delta P \quad$ Pressure drop across the test sec tion $(\mathrm{Pa})$

$R \quad$ Specific gas constant $\left(\mathrm{J} \cdot \mathrm{Kg}^{-1} \cdot \mathrm{K}^{-1}\right)$

Re Reynolds number (-)

$S \quad$ Sutherland constant value $(\mathrm{K})$

$T_{a m} \quad$ Working fluid ambient temperature $\left({ }^{\circ} \mathrm{C}\right)$

$T_{\text {in }} \quad$ Fluid input temperature $\left({ }^{\circ} \mathrm{C}\right)$

$T_{\text {out }} \quad$ Fluid output temperature $\left({ }^{\circ} \mathrm{C}\right)$

$T_{S} \quad$ Surface temperature $\left({ }^{\circ} \mathrm{C}\right)$

$t_{H X} \quad H X$ temperature coefficient $\left({ }^{\circ} \mathrm{C}\right)$

$V \quad$ Flow velocity $\left(\mathrm{m} \cdot \mathrm{s}^{-1}\right)$

$v \quad$ Kinematic viscosity $\left(\mathrm{m}^{2} \cdot \mathrm{s}^{-1}\right)$

$W \quad$ Test section width (m)

$\lambda \quad$ Thermal conductivity of fluid $\left(\mathrm{W} \cdot \mathrm{m}^{-1} \cdot \mathrm{K}^{-1}\right)$

$\rho \quad$ Fluid density $\left(\mathrm{kg} \cdot \mathrm{m}^{-3}\right)$ 


\section{References}

1. Jasim, H.H. Thermal performance improvement based on the hybrid design of a heat sink. Eng. Sci. Technol. Int. J. 2020, 23, 1144-1152. [CrossRef]

2. Shah, R.K.; Sekulic, D.P. Fundamentals of Heat Exchanger Design; John Wiley \& Sons: Hoboken, NJ, USA, 2003.

3. Wong, M.; Owen, I.; Sutcliffe, C.; Puri, A. Convective heat transfer and pressure losses across novel heat sinks fabricated by Selective Laser Melting. Int. J. Heat Mass Transf. 2009, 52, 281-288. [CrossRef]

4. Feng, S.; Li, F.; Zhang, F.; Lu, T.J. Natural convection in metal foam heat sinks with open slots. Exp. Therm. Fluid Sci. 2018, 91, 354-362. [CrossRef]

5. Bashir, A.I.; Everts, M.; Bennacer, R.; Meyer, J.P. Single-phase forced convection heat transfer and pressure drop in circular tubes in the laminar and transitional flow regimes. Exp. Therm. Fluid Sci. 2019, 109, 109891. [CrossRef]

6. Kim, S.Y.; Paek, J.W.; Kang, B.H. Thermal performance of aluminum-foam heat sinks by forced air cooling. IEEE Trans. Compon. Packag. Technol. 2003, 26, 262-267.

7. Wong, M.; Tsopanos, S.; Sutcliffe, C.J.; Owen, I. Selective laser melting of heat transfer devices. Rapid Prototyp. J. 2007, 13, $291-297$. [CrossRef]

8. Ventola, L.; Robotti, F.; Dialameh, M.; Calignano, F.; Manfredi, D.; Chiavazzo, E.; Asinari, P. Rough surfaces with enhanced heat transfer for electronics cooling by direct metal laser sintering. Int. J. Heat Mass Transf. 2014, 75, 58-74. [CrossRef]

9. Oguntala, G.; Abd-Alhameed, R.; Sobamowo, G.; Abdullahi, H.-S. Improved thermal management of computer microprocessors using cylindrical-coordinate micro-fin heat sink with artificial surface roughness. Eng. Sci. Technol. Int. J. 2018, $21,736-744$. [CrossRef]

10. Kuron, D. ASTM manual on „coating and lining methods for cooling water systems in power plants”. Von John C. Monday, Timothy B. Shugart, and Joseph A. Tamayo, 72 Seiten, 6 Abbildungen, 3 Tabellen, American Society for Testing and Materials (ASTM), ASTM Manual Series MNL 28, Philadelphia, PA 19103, 1995.£ 30.00, ISBN 0-8031-2070-2. In Europa zu beziehen durch: American Technical Publishers Ltd., 27-29 Knowl Piece, Wilbury Way, Hitchin, Herts. SG4 0SX. England. Mater. Corros. 1997, 48, 134. [CrossRef]

11. Thompson, S.M.; Aspin, Z.S.; Shamsaei, N.; Elwany, A.; Bian, L. Additive manufacturing of heat exchangers: A case study on a multi-layered Ti-6Al-4V oscillating heat pipe. Addit. Manuf. 2015, 8, 163-174. [CrossRef]

12. Caccia, M.; Tabandeh-Khorshid, M.; Itskos, G.; Strayer, A.; Caldwell, A.; Pidaparti, S.; Singnisai, S.; Rohskopf, A.; Schroeder, A.; Jarrahbashi, D. Ceramic-metal composites for heat exchangers in concentrated solar power plants. Nature 2018, 562, 406. [CrossRef]

13. Dede, E.M.; Joshi, S.N.; Zhou, F. Topology optimization, additive layer manufacturing, and experimental testing of an air-cooled heat sink. J. Mech. Des. 2015, 137, 111403. [CrossRef]

14. Arie, M.A.; Shooshtari, A.H.; Ohadi, M.M. Experimental characterization of an additively manufactured heat exchanger for dry cooling of power plants. Appl. Therm. Eng. 2018, 129, 187-198. [CrossRef]

15. Bernardin, J.D.; Ferguson, K.; Sattler, D.; Kim, S.-J. The design, analysis, and fabrication of an additively manufactured twisted tube heat exchanger. In Proceedings of the ASME 2017 Heat Transfer Summer Conference, Bellevue, WA, USA, 9-12 July 2017.

16. Kong, D.; Zhang, Y.; Liu, S. Convective heat transfer enhancement by novel honeycomb-core in sandwich panel exchanger fabricated by additive manufacturing. Appl. Therm. Eng. 2019, 163, 114408. [CrossRef]

17. Jafari, D.; Wits, W.W. The utilization of selective laser melting technology on heat transfer devices for thermal energy conversion applications: A review. Renew. Sustain. Energy Rev. 2018, 91, 420-442. [CrossRef]

18. Cobbinah, P.V.; Nzeukou, R.A.; Onawale, O.T.; Matizamhuka, W.R. Laser Powder Bed Fusion of Potential Superalloys: A Review. Metals 2021, 11, 58. [CrossRef]

19. Bhavar, V.; Kattire, P.; Patil, V.; Khot, S.; Gujar, K.; Singh, R. A review on powder bed fusion technology of metal additive manufacturing. In Proceedings of the 4th International conference and exhibition on Additive Manufacturing Technologies-AM2014, Bangalore, India, 1-2 September 2014; pp. 1-2.

20. Wong, K.; Ho, J.; Leong, K.; Wong, T. Fabrication of heat sinks by selective laser melting for convective heat transfer applications. Virtual Phys. Prototyp. 2016, 11, 159-165. [CrossRef]

21. Collins, I.L.; Weibel, J.A.; Pan, L.; Garimella, S.V. Experimental Characterization of a Microchannel Heat Sink Made by Additive Manufacturing. In Proceedings of the 2018 17th IEEE Intersociety Conference on Thermal and Thermomechanical Phenomena in Electronic Systems (ITherm), San Diego, CA, USA, 29 May-1 June 2018; pp. 171-177.

22. Gerstler, W.D.; Erno, D. Introduction of an additively manufactured multi-furcating heat exchanger. In Proceedings of the 2017 16th IEEE Intersociety Conference on Thermal and Thermomechanical Phenomena in Electronic Systems (ITherm), Lake Buena Vista, FL, USA, 30 May-2 June 2017; pp. 624-633.

23. McDonough, J. A perspective on the current and future roles of additive manufacturing in process engineering, with an emphasis on heat transfer. Therm. Sci. Eng. Prog. 2020, 19, 100594. [CrossRef]

24. Najmon, J.C.; Raeisi, S.; Tovar, A. Review of additive manufacturing technologies and applications in the aerospace industry. In Additive Manufacturing for the Aerospace Industry; Elsevier: Amsterdam, The Netherlands, 2019; pp. 7-31.

25. Bisht, M.; Ray, N.; Verbist, F.; Coeck, S. Correlation of selective laser melting-melt pool events with the tensile properties of Ti-6Al-4V ELI processed by laser powder bed fusion. Addit. Manuf. 2018, 22, 302-306. [CrossRef] 
26. Vafadar, A.; Guzzomi, F.; Rassau, A.; Hayward, K. Advances in Metal Additive Manufacturing: A Review of Common Processes, Industrial Applications, and Current Challenges. Appl. Sci. 2021, 11, 1213. [CrossRef]

27. Kruth, J.-P.; Mercelis, P.; Van Vaerenbergh, J.; Craeghs, T. Feedback control of selective laser melting. In Proceedings of the 3rd International Conference on Advanced Research in Virtual And Rapid Prototyping, Leiria, Portugal, 17-22 September 2007; pp. 521-527.

28. Moussaoui, K.; Rubio, W.; Mousseigne, M.; Sultan, T.; Rezai, F. Effects of Selective Laser Melting additive manufacturing parameters of Inconel 718 on porosity, microstructure and mechanical properties. Mater. Sci. Eng. A 2018, 735, 182-190. [CrossRef]

29. Sahoo, R.R.; Ghosh, P.; Sarkar, J. Energy and exergy comparisons of water based optimum brines as coolants for rectangular fin automotive radiator. Int. J. Heat Mass Transf. 2017, 105, 690-696. [CrossRef]

30. Turkyilmazoglu, M. Stretching/shrinking longitudinal fins of rectangular profile and heat transfer. Energy Convers. Manag. 2015, 91, 199-203. [CrossRef]

31. Abbott, H.; Doenhoff, E.; Lous, S.; Stivers, J. National Advisory Commitee for Aeronautics Report No. 824: Summary of Airfoil Data. 1945. Available online: https://ntrs.nasa.gov/api/citations/19930090976/downloads/19930090976.pdf (accessed on 20 February 2021).

32. Ho, J.Y.; Wong, K.K.; Leong, K.C.; Wong, T.N. Convective heat transfer performance of airfoil heat sinks fabricated by selective laser melting. Int. J. Therm. Sci. 2017, 114, 213-228. [CrossRef]

33. Ravi, R.K.; Saini, R. Nusselt number and friction factor correlations for forced convective type counter flow solar air heater having discrete multi $\mathrm{V}$ shaped and staggered rib roughness on both sides of the absorber plate. Appl. Therm. Eng. 2018, 129, 735-746. [CrossRef]

34. Tahat, M.; Kodah, Z.; Jarrah, B.; Probert, S. Heat transfers from pin-fin arrays experiencing forced convection. Appl. Energy 2000, 67, 419-442. [CrossRef]

35. Jubran, B.; AI-Salaymeh, A. Heat transfer enhancement in electronic modules using ribs and "film-cooling-like" techniques. Int. J. Heat Fluid Flow 1996, 17, 148-154. [CrossRef]

36. Jones, F.E. The air density equation and the transfer of the mass unit. J. Res. Natl. Bur. Stand. 1978, 83, 419-428. [CrossRef]

37. Du, S.; Tong, Z.-X.; Zhang, H.-H.; He, Y.-L. Tomography-based determination of Nusselt number correlation for the porous volumetric solar receiver with different geometrical parameters. Renew. Energy 2019, 135, 711-718. [CrossRef]

38. White, F.M.; Corfield, I. Viscous Fluid Flow; McGraw-Hill: New York, NY, USA, 2006; Volume 3.

39. Sahin, B.; Ates, I.; Manay, E.; Bayrakceken, A.; Celik, C. Optimization of design parameters for heat transfer and friction factor in a heat sink with hollow trapezoidal baffles. Appl. Therm. Eng. 2019, 154, 76-86. [CrossRef]

40. Moghadassi, A.; Ghomi, E.; Parvizian, F. A numerical study of water based Al2O3 and Al2O3-Cu hybrid nanofluid effect on forced convective heat transfer. Int. J. Therm. Sci. 2015, 92, 50-57. [CrossRef]

41. Hans, V.; Gill, R.; Singh, S. Heat transfer and friction factor correlations for a solar air heater duct roughened artificially with broken arc ribs. Exp. Therm. Fluid Sci. 2017, 80, 77-89. [CrossRef] 